\title{
Study of Antiultraviolet Asphalt Modifiers and Their Antiageing Effects
}

\author{
Jinxuan Hu, ${ }^{1}$ Shaopeng Wu, ${ }^{1}$ Quantao Liu, ${ }^{1}$ María Inmaculada García Hernández, \\ Wenbo Zeng, ${ }^{1}$ and Wenhua Xie ${ }^{2}$ \\ ${ }^{1}$ State Key Laboratory of Silicate Materials for Architectures, Wuhan University of Technology, Wuhan, China \\ ${ }^{2}$ Wuhan Youfeng Moulding Co. Ltd., Wuhan, China \\ Correspondence should be addressed to Shaopeng Wu; wusp@whut.edu.cn
}

Received 10 June 2017; Accepted 31 July 2017; Published 7 September 2017

Academic Editor: Frederic Dumur

Copyright (C) 2017 Jinxuan Hu et al. This is an open access article distributed under the Creative Commons Attribution License, which permits unrestricted use, distribution, and reproduction in any medium, provided the original work is properly cited.

Ultraviolet (UV) radiation causes serious ageing problems on pavement surface. In recent years, different UV blocking materials have been used as modifiers to prevent asphalt ageing during the service life of the pavement. In this study, three different materials have been used as modifiers in base asphalt to test their UV blocking effects: layered double hydroxides (LDHs), organomontmorillonite (OMMT), and carbon black (CB). UV ageing was applied to simulate the ageing process and softening point, penetration, ductility, DSR (Dynamic Shear Rheometer) test, and Fourier Transform Infrared Spectroscopy (FTIR) test were conducted to evaluate the anti-UV ageing effects of the three UV blocking modifiers. Physical property tests show that base asphalt was influenced more seriously by UV radiation compared to the modified asphalt. DSR test results indicate that the complex modulus of asphalt before UV ageing is increased because of modifiers, while the complex modulus of base asphalt after UV ageing is higher than that of the modified asphalt, which shows that the UV blocking modifiers promote the antiageing effects of asphalt. FTIR test reveals that the increment of carbonyl groups and sulfoxide groups of modified asphalt is less than that in base asphalt. Tests indicate the best UV blocking effect results for samples with LDHs and the worst UV blocking effect results for samples with CB.

\section{Introduction}

Asphalt has been used for road construction for more than a century [1-3]. Compared with cement pavement, asphalt pavement has remarkable advantages in comfortableness and smoothness [4, 5]. However, the UV radiation leads to a shorter lifespan of the pavement. A set of complex physicochemical processes happen because of the exposition of the asphalt pavement to UV radiation and result in a harder and more brittle asphalt $[6,7]$; as a result, low temperature cracking and fatigue cracks are more likely to occur on the pavement $[8,9]$. Under these circumstances, it is an urgent task to develop the method to prevent the ageing of asphalt.

Thermooxidative degradation of asphalt has been investigated deeply, but the effects of UV radiation on asphalt binder ageing have been given little attention in previous researches [10]. Although some researchers [11, 12] showed that UV radiation only affects the upper layers of asphalt pavement, the effect of UV radiation on asphalt cannot be ignored. Studies [13] have shown that UV radiation after RTFOT could age a thin film of asphalt to the same ageing level as the one aged by PAV in a few hours.

Researchers adopted modifiers such as UV absorbents $[14,15]$, LDHs [16-18], and nanomaterials [19] to improve the UV ageing resistance of asphalt. $\mathrm{CB}$ is an organic protective material with high absorbance to UV radiation, as a UV absorber has the potential to improve the UV ageing resistance and enhances the low temperature properties [20]. Cong et al. [10] used CB to reflect and absorb UV radiation in asphalt. Results show that low temperature properties of $\mathrm{CB}$ modified asphalt were better than unmodified asphalt after UV ageing.

Montmorillonite (MMT) nanocomposite is a phyllosilicate nanomaterial which has been used for the modification of polymers [21, 22]. Nanosize layers of MMT could be dispersed into the polymer matrix due to the fact that polymer 
TABLE 1: Physical properties of BA.

\begin{tabular}{lc}
\hline Physical properties & BA \\
\hline Softening point $\left({ }^{\circ} \mathrm{C}\right)$ & 45.4 \\
Penetration $\left(25^{\circ} \mathrm{C}, 0.1 \mathrm{~mm}\right)$ & 90.9 \\
Ductility $\left(10^{\circ} \mathrm{C}, 1 \mathrm{~cm} / \mathrm{min}\right)$ & 170 \\
Viscosity $\left(60^{\circ} \mathrm{C}, \mathrm{pa} \cdot \mathrm{s}\right)$ & 205 \\
Viscosity $\left(135^{\circ} \mathrm{C}, \mathrm{pa} \cdot \mathrm{s}\right)$ & 0.439 \\
\hline
\end{tabular}

chains can intercalate into the interlayer of MMT [23, 24]. Previous researches investigated the effects of OMMT on the physical properties of asphalt and found a positive effect [25, 26]. Zhang et al. [27, 28] modified SBS asphalt with OMMT and found that OMMT could improve the UV ageing resistance of asphalt.

In recent years the use of LDHs as antiageing agent to improve the asphalt ageing resistance has attracted much attention [17]. LDHs are a anionic compound with sheetlike structure [29]. Previous researches indicate that LDHs could improve the UV ageing resistance of asphalt because their shielding physical structure and their chemical UV light absorption properties $[18,30]$. UV blocking materials have been used by some researchers to improve the UV ageing resistance of asphalt. Liu et al. [31, 32] used LDHs as a UV blocking and absorbing material in asphalt. In their research, the rheological properties and fatigue properties of LDHs modified asphalt and its mixture were improved greatly with LDHs. However, there is no research about the antiageing effects of these UV blocking materials. So in this study, LDHs, OMMT, and CB were used as asphalt modifiers to prepare anti-UV ageing asphalt. Softening point, penetration, ductility, DSR test, and FTIR tests were conducted to evaluate anti-UV ageing effects of the three UV blocking materials.

\section{Experiment Materials}

2.1. Materials. Three UV blocking materials (LDHs, OMMT, and $\mathrm{CB}$ ) were used as modifiers in this research to prepare anti-UV ageing asphalt, because they were frequently used as antiageing materials in the previous research. Base asphalt (BA) with $80 / 100$ pen grade was the matrix. The physical properties of the asphalt used are listed in Table 1.

The molecule structure of modifiers is illustrated in Figures 1-3. As shown in Figure 1, LDHs are a kind of anion layered material which consists of interlayer galleries filled with electrically balanced anions, along with hydration water molecules and basal layers with positively charged metal hydroxide. The chemical formula of $\mathrm{LDHs}$ could be descripted as $\left[\mathrm{M}^{2+}{ }_{1-X} \mathrm{M}^{3+}{ }_{X}(\mathrm{OH})_{2}\right]^{X+}-\left(\mathrm{A}^{n-} \mathrm{X} / n\right) \cdot m \mathrm{H}_{2} \mathrm{O}$, where $\mathrm{M}^{2+}$ was divalent metal cation and $\mathrm{M}^{3+}$ was trivalent. The subscript $X$ was the molar ratio equal to $\mathrm{M}^{3+} /\left(\mathrm{M}^{2+}+\right.$ $\mathrm{M}^{3+}$ ), which ranges from 0.2 to 0.33 . $\mathrm{A}^{n-}$ represents the exchangeable $n$-valent anion. A part of $\mathrm{M}^{2+}$ in the layers is replaced by $\mathrm{M}^{3+}$ because of isomorphous substitution, which let the layers have a positive electric charge. And $\mathrm{A}^{n-}$ between the layers maintains the system charge balance. The special structural composition of LDHs results in regulation of composition in the layers and anion between the layers [18, 33].

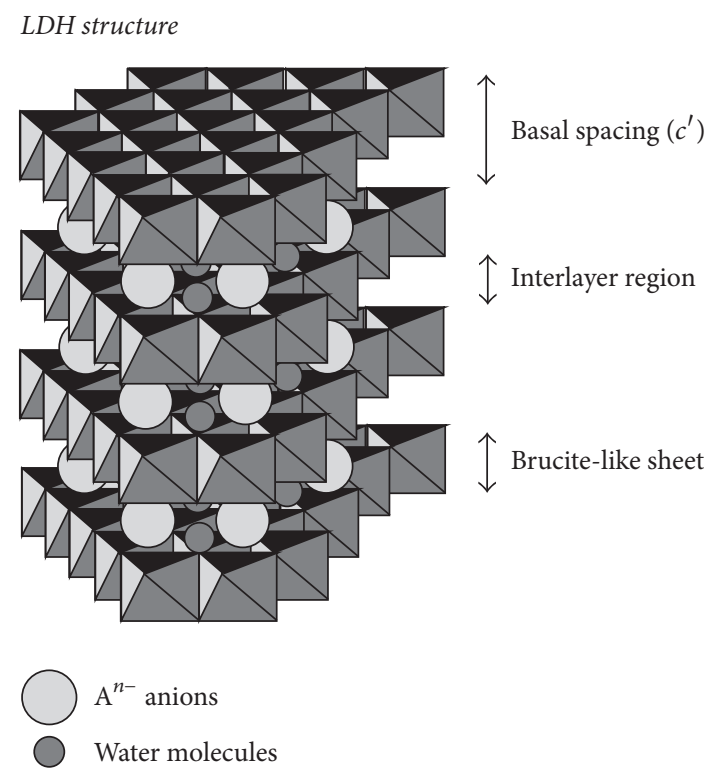

Octahedral unit

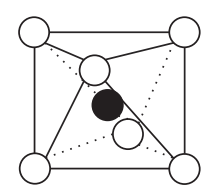

$\mathrm{M}^{2+}$ or $\mathrm{M}^{3+}$ metal cation
$\mathrm{OH}^{-}$anion

FIGURE 1: The molecule structure of LDHs [33].

MMt is a layered silicate mineral, whose chemical formula is $(\mathrm{Na}, \mathrm{Ca})_{0.33}(\mathrm{Al}, \mathrm{Mg})_{2}\left(\mathrm{Si}_{4} \mathrm{O}_{10}\right)(\mathrm{OH})_{2}$. It consists of a $2: 1$ type layer structure, one octahedral sandwiched by two tetrahedrons, as shown in Figure 2. The thickness of a single MMt layer is around $1 \mathrm{~nm}$ and the cross-sectional area is $100 \mathrm{~nm}^{2}$. Between the layers, there are some hydrated cations, such as $\mathrm{Na}^{+}$. In order to make the MMt more compatible with polymer, it is usually modified by some surfactants, such as quaternary ammonium salt. After being modified, the interlayer hydrated cations will be replaced by organic cations. In this way, organophilic will replace the normally hydrophilic silicate surface $[34,35]$, and the Mt becomes OMMT.

CB could be generated when gaseous or liquid hydrocarbon conducts incomplete combustion or hot crack under insufficient oxygen. The component of CB consists of a great deal of carbon and a little bit of oxygen, hydrogen, sulfur, water, and other impurities, as shown in Figure 3. The basic building blocks of $\mathrm{CB}$ particles are the individual graphitic layers. In a single CB particle, small crystallites are randomly oriented, which is different from graphite. The fundamental units are aggregates comprised of particles but the particles appear to be continuous on the lattice scale within the same aggregate [36, 37].

2.2. Preparation of Modified Asphalt. Melting asphalt was added to a mixing container where the bitumen was modified 


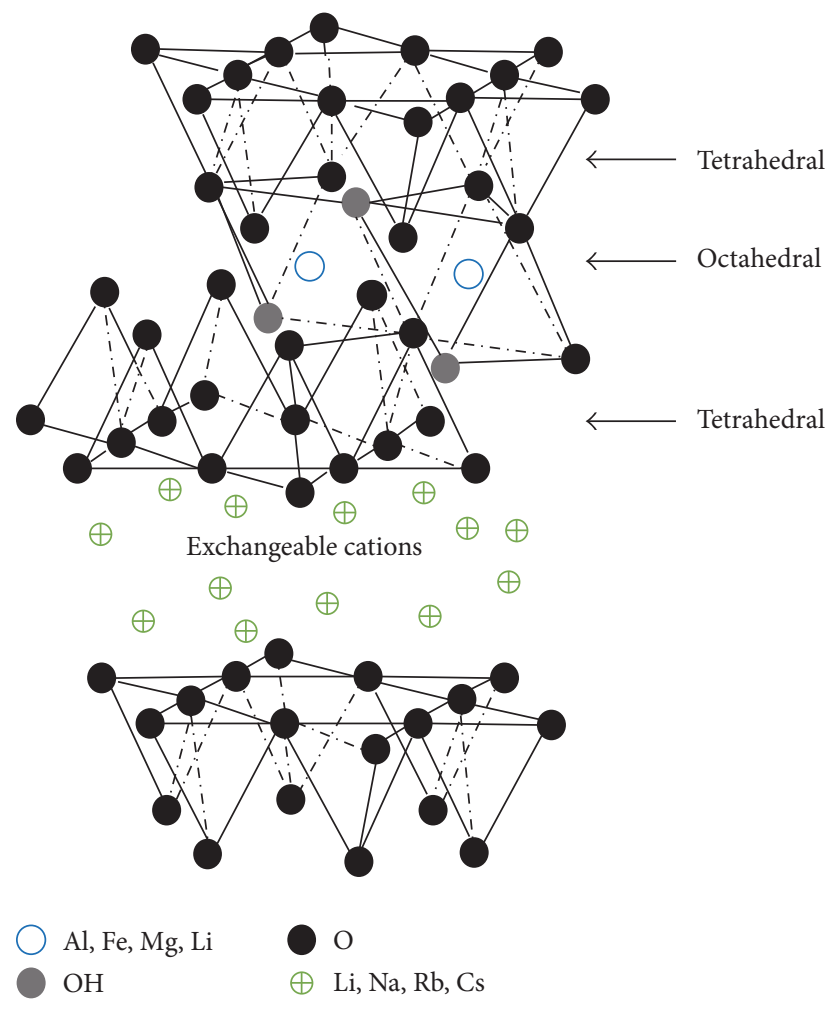

Figure 2: The molecule structure of MMT [34].

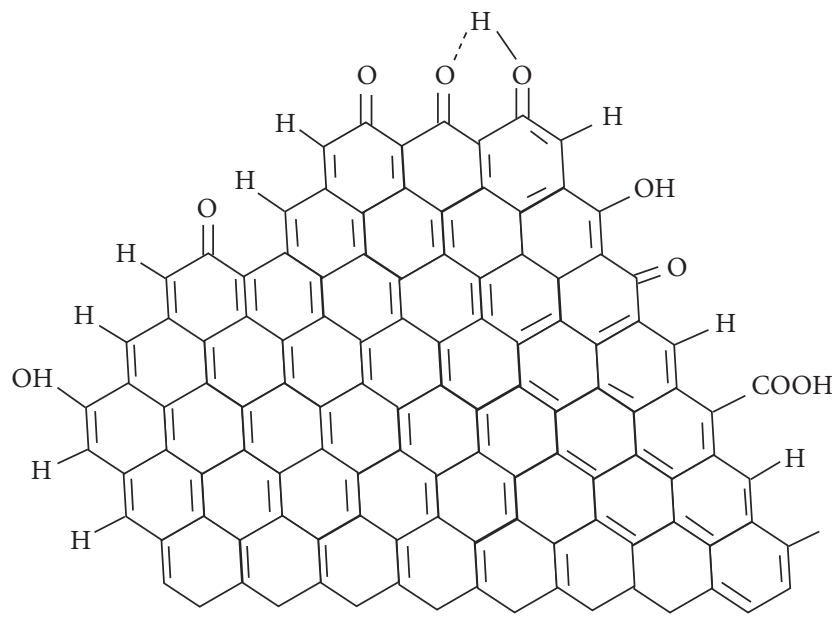

Figure 3: The molecule structure of CB [37].

with 3 wt\% of UV blocking material. An oil-bath heating container was applied to heat the asphalt at about $150 \pm$ $5^{\circ} \mathrm{C}$. When temperature reached the target temperature, high speed shear mixer was used to disperse the modifier. Finally, $4000 \mathrm{r} / \mathrm{min}$ rotation speed for $60 \mathrm{~min}$ [31] was applied to ensure a homogeneous modified asphalt. BA was also treated with the same process to eliminate the preparation effects, which might lead to experimental error. LMA, OMA, and CMA are the acronyms for LDHs modified asphalt, OMMT modified asphalt, and CB modified asphalt, respectively.

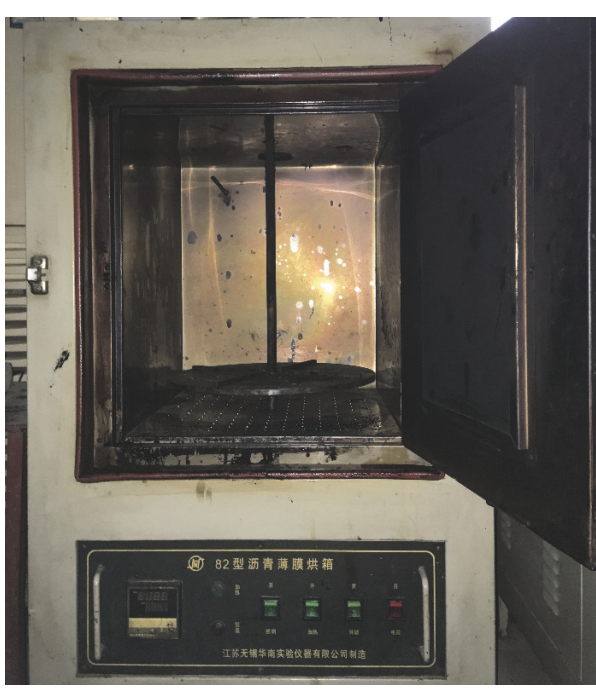

FIgURE 4: TFOT oven.

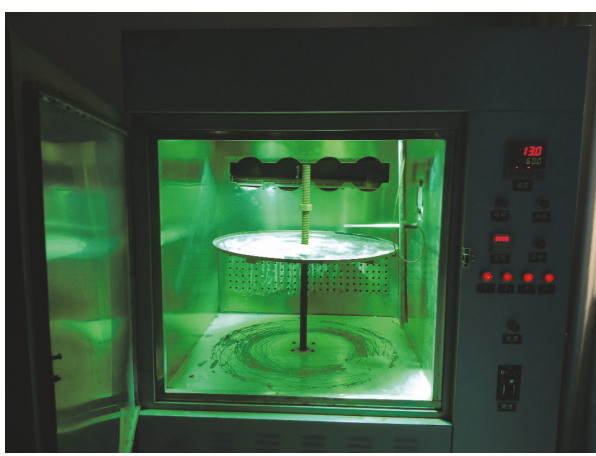

FIGURE 5: UV chamber.

2.3. Ageing Procedure. A UV chamber was used to simulate the UV ageing of asphalt. In the top of the chamber, there are four UV lamps on four corners in order to ensure homogeneous UV intensity. The samples previously experienced TFOT (ASTM D 1754) and were placed on a rotary table in the UV chamber. The main wavelength of UV lamp was $365 \mathrm{~nm}$. And the average density of UV radiation on asphalt surface is about $500 \mu \mathrm{w} / \mathrm{cm}^{2}$. This procedure was performed for the samples for 10 days as the UV ageing time. The figures of TFOT oven and UV chamber are shown in Figures 4 and 5. Asphalt was poured into $\Phi(140 \pm 0.5) \mathrm{mm}$ iron pan and the thickness of samples was $1.3 \mathrm{~mm}$.

\section{Test Methods}

3.1. Physical Properties Test. The penetration, softening point, and ductility of the samples were tested in accordance with the standards ASTM D36-76, ASTM D5-13, and ASTM D11399 , respectively.

3.2. Dynamic Shear Rheometer (DSR) Test. Rheological properties of asphalt can be measured by DSR test. In this paper, strain sweep test, high temperature sweep test, and 
low temperature sweep test were performed. DSR tests were adopted under the strain-controlled mode, whose constant load frequency was $10 \mathrm{rad} / \mathrm{s}$. In the strain sweep test, the strain level was conducted applying first $0.005 \%$ strain amplitude to a specimen, which was continuously increased until nonlinearity appeared in the response. The test temperature was $60^{\circ} \mathrm{C}$.

During the high temperature sweep test, temperature increased from $30^{\circ} \mathrm{C}$ to $80^{\circ} \mathrm{C}$ with $2^{\circ} \mathrm{C} / \mathrm{min}$ increment. The diameter of the plate was $25 \mathrm{~mm}$ and the gap between parallel plates was $1 \mathrm{~mm}$. During the low temperature sweep test, temperature increased from $-10^{\circ} \mathrm{C}$ to $30^{\circ} \mathrm{C}$ with $2^{\circ} \mathrm{C} / \mathrm{min}$ increment. The diameter of the plate was $8 \mathrm{~mm}$ and the gap between parallel plates was $2 \mathrm{~mm}$. The strain level applied during the high temperature sweep tests and low temperature tests was $0.5 \%$ and $0.05 \%$ strain amplitude, respectively. Complex modulus $\left(G^{*}\right)$ and phase angle $(\delta)$ could be obtained from the DSR test, which are important evaluation indices for asphalt rheological properties before and after UV ageing.

3.3. Fourier Transform Infrared Spectroscopy. The ageing index of asphalt can be conveniently measured by FTIR tests. Asphalt binders were dissolved into carbon disulfide to prepare $5 \mathrm{wt} \%$ solutions. Then a drop of solution was added to a KBr cell. After carbon disulfide evaporated, the thin asphalt film was prepared as FTIR sample. The scan range is from $3000 \mathrm{~cm}^{-1}$ to $600 \mathrm{~cm}^{-1}$ with a resolution of $4 \mathrm{~cm}^{-1}$.

The carbonyl function $\mathrm{C}=\mathrm{O}\left(1700 \mathrm{~cm}^{-1}\right)$ and sulfoxide $\mathrm{S}=\mathrm{O}\left(1032 \mathrm{~cm}^{-1}\right)$ are calculated by the peak areas of themselves. The carbonyl function index and sulfoxide index can be calculated by the following equations $[38,39]$ :

$$
\begin{aligned}
& I_{\mathrm{C}=\mathrm{O}} \\
& =\frac{\text { Area of carbonyle band centered around } 1700 \mathrm{~cm}^{-1}}{\sum \text { Area of spectral bands between } 2000 \wedge 600 \mathrm{~cm}^{-1}} \\
& I_{\mathrm{S}=\mathrm{O}} \\
& =\frac{\text { Area of ethylene band centered around } 1030 \mathrm{~cm}^{-1}}{\sum \text { Area of spectral bands between } 2000 \wedge 600 \mathrm{~cm}^{-1}} .
\end{aligned}
$$

\section{Results and Discussion}

4.1. Softening Point. Figure 6 shows that all the three anti-UV ageing materials increased the softening point of the asphalt binder and CB modified asphalt shows the biggest increment of the softening point temperature compared to the BA sample. The softening point temperatures of LDHs and OMMT modified asphalt are $45.3^{\circ} \mathrm{C}$ and $45.6^{\circ} \mathrm{C}$, respectively. The reason why $\mathrm{CB}$ modified asphalt shows higher increment is that the higher specific surface area of $\mathrm{CB}$ would absorb light components (aromatic and saturation); this leads to a worse deforming ability and a higher softening point value. After the UV ageing process, all the samples present an increment in the softening point and the BA showed the highest increment compared to the three modified asphalt samples, which means that the anti-UV ageing materials could alleviate the UV ageing of asphalt. And the softening

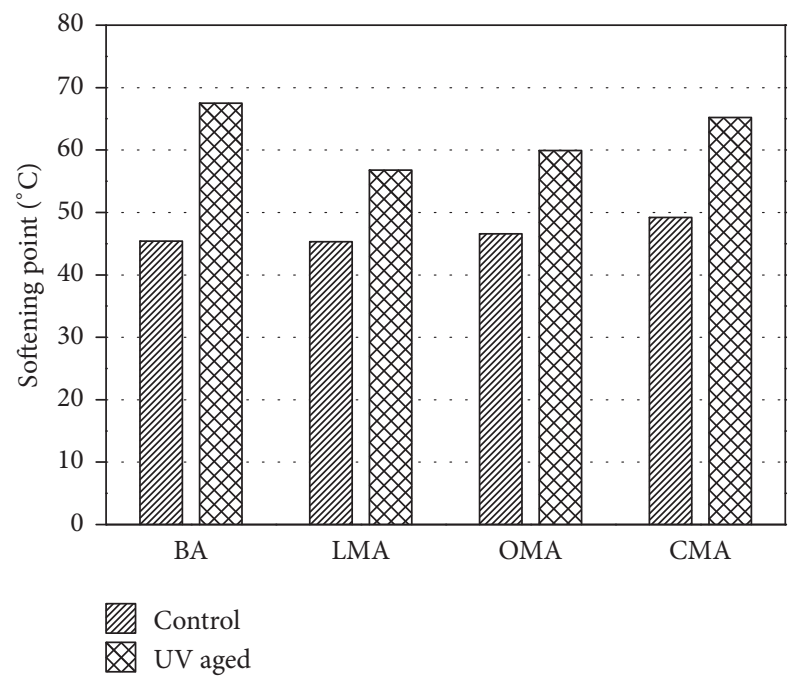

FIGURE 6: Softening point of UV aged and unaged asphalt.

point increments of LDHs modified asphalt and OMMT are almost the same which are much lower than that of $\mathrm{CB}$ modified asphalt. This indicates that LHDs and OMMT could significantly prevent asphalt ageing during UV radiation. And the antiageing effect of $\mathrm{CB}$ is limited compared to the other two UV blocking materials.

4.2. Penetration. Penetration reflects the hardness of asphalt and indicates the ageing index of asphalt after UV ageing. Smaller penetration means more serious ageing. From Figure 7 , it can be seen that the penetration value declines for all four asphalt samples after UV ageing. The penetration values of the three modified asphalt samples are much higher compared to base asphalt. The penetration decrement of LDHs modified asphalt is the smallest, and the penetration decrement of $\mathrm{CB}$ modified asphalt is the highest in the three modified asphalt samples. The penetration results are in concordance with the softening point results. The anti-UV ageing effects of LDHs and OMMT are better than CB.

4.3. Ductility. Results of ductility are presented in Table 2. Incorporation of LDHs, OMMT, and $\mathrm{CB}$ decreased the ductility of asphalt by $16 \%, 26 \%$, and $37 \%$, respectively. But after UV ageing, ductility values of three anti-UV ageing materials of modified asphalt were higher than aged base asphalt. For LDHs modified asphalt was highest and for $\mathrm{CB}$ it was smallest. The rate of the loss of ductility was reduced greatly by the incorporation of UV barrier materials. Ultraviolet blocking materials dispersed in asphalt could reflect and absorb UV radiation and reduced the loss rate of light component in asphalt, which leads to a higher residual ductility during UV ageing process.

\subsection{Rheological Properties}

4.4.1. Strain Sweep Test. There are various test methods to measure the rheological properties: temperature sweep test, 
TABLE 2: Ductility of UV aged and unaged asphalt.

\begin{tabular}{lcc}
\hline Asphalt & Original ductility $(\mathrm{cm})$ & Ductility after UV ageing $(\mathrm{cm})$ \\
\hline BA & 170 & 41 \\
LMA & 142 & 62 \\
OMA & 126 & 52 \\
CMA & 107 & 45 \\
\hline
\end{tabular}

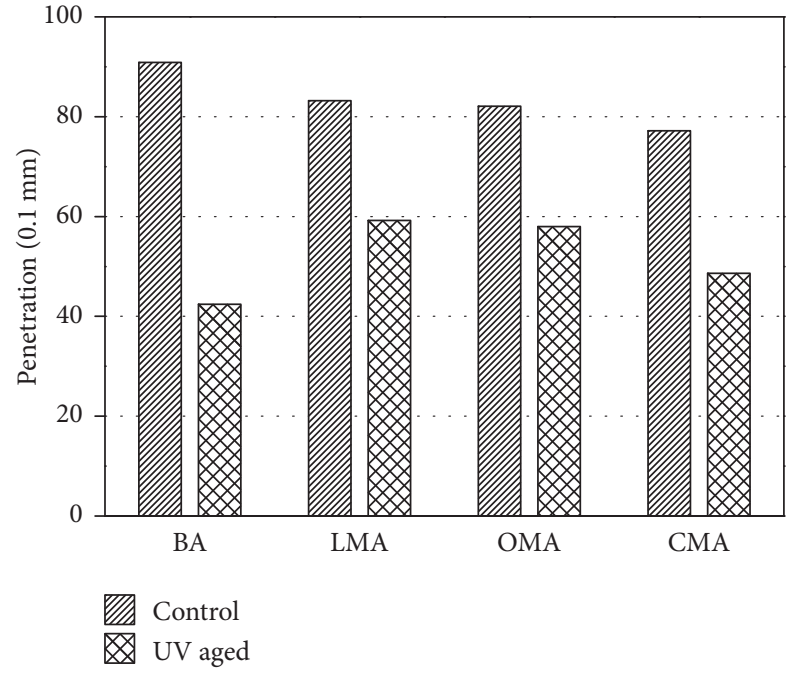

FIGURE 7: Penetration of UV aged and unaged asphalt.

frequency sweep test, and sheer creep test. The shear stress applied in these tests must be low enough to keep the measurement inside the region of linear viscoelastic (LVE). In this LVE region, the sum of responses to an individual stress is equal to the sum of stresses [40]. The LVE strain limit represents the deformation where molecular structure of materials begins to experience irreversible changes [41]. Tests on asphalt must be done inside the LVE region to ensure test repeatability. The dynamic shear modulus is relatively independent of the strain applied at sufficiently small strains. Therefore, the strain level or stress level must be selected so that the resulting response $\left(G^{*}\right)$ is within the LVE limit. The LVE strain limit was defined as the strain value at which the complex modulus has decreased to $95 \%$ of its initial value by Airey et al. [42].

The strain sweep tests were performed firstly with the purpose of determining the limits of the LVE region and stress range. $G^{*}$ and stress $(\sigma)$ of UV aged and unaged asphalt versus strain are shown in Figures 8 and 9. Tendencies of $G^{*}$ and $\sigma$ of unaged asphalt stay at a similar level. The LVE strain limits of several kinds of unaged asphalt are similar, and the LVE strain limits of several kinds of unaged asphalt are smaller than aged asphalt. But for aged asphalt and unaged asphalt, $0.05 \%$ and $0.5 \%$ strain amplitude are sufficiently small for the following temperature sweep tests.

4.4.2. High Temperature Sweep. Dynamic viscoelastic performances are an important part of asphalt rheological properties, which depends strongly on temperature and

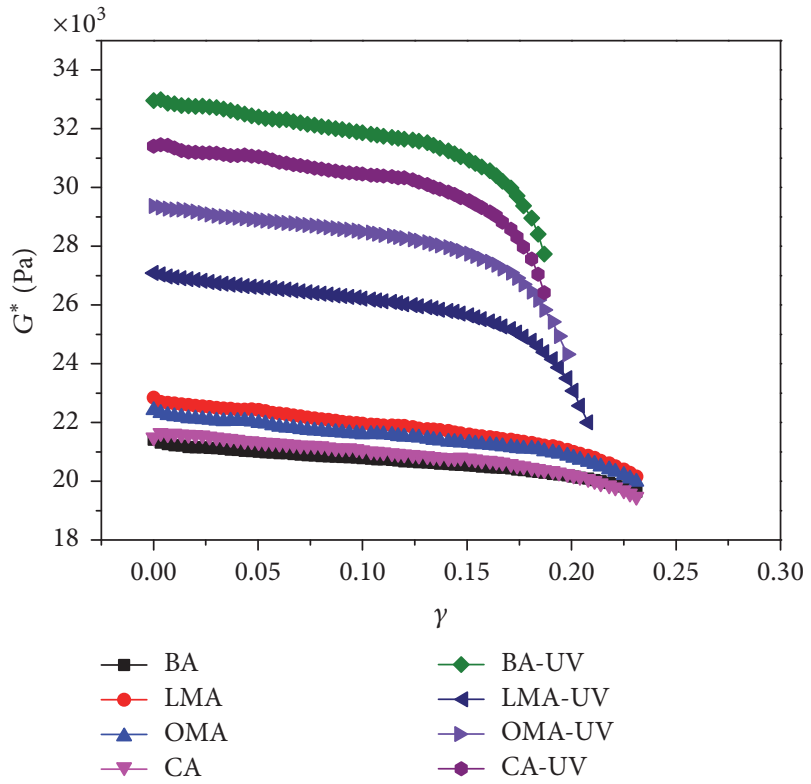

FIGURE 8: $G^{*}$ of UV aged and unaged asphalt versus strain.

loading frequency [43]. There are several parameters such as $G^{*}$ and $\delta$ which can represent the principal viscoelastic performance. $G^{*}$ represents the ratio between maximum stress and maximum strain, which shows the deformation resistance ability of asphalt [44]. In other words, the higher complexity the modulus has, the higher the deformation resistance ability becomes. $G^{*}$ of both base and modified asphalt before and after ageing from $30^{\circ} \mathrm{C}$ to $80^{\circ} \mathrm{C}$ is shown in Figure 10. For asphalt ageing, the higher complexity the modulus has, the higher the ageing degree becomes. It can be seen that $G^{*}$ of base asphalt is lower than $G^{*}$ of modified asphalt before UV ageing. It means that asphalt ability for deformation resistance is increased with additives. $G^{*}$ of LMA and OMA is higher than CMA, which means that LDHs and OMMT have a stronger effect for improving the deformation resistance than CB. $G^{*}$ of modified asphalt is lower than $G^{*}$ of base asphalt after UV ageing, which shows that UV ageing resistance of asphalt is increased by modifiers; besides it can be seen that $G^{*}$ of LMA-UV and OMA-UV is lower than CA-UV. The results indicate that the anti-UV ageing effects of LDHs and OMMT are better than CB.

$\delta$ describes the time between the applied stress and the generated strain, which shows viscosity and elasticity characteristics of asphalt [45]. With the decrease of $\delta$, the time is shortened. Lower phase angle means higher ageing degree of asphalt. $\delta$ of base and modified asphalt before and 


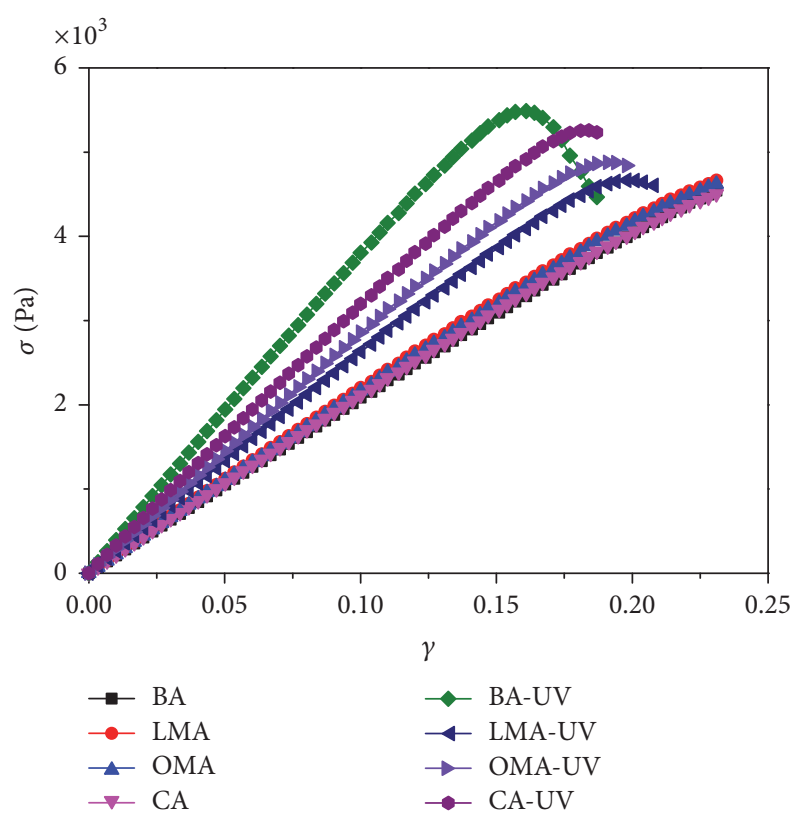

FIGURE 9: Stress of UV aged and unaged asphalt versus strain.

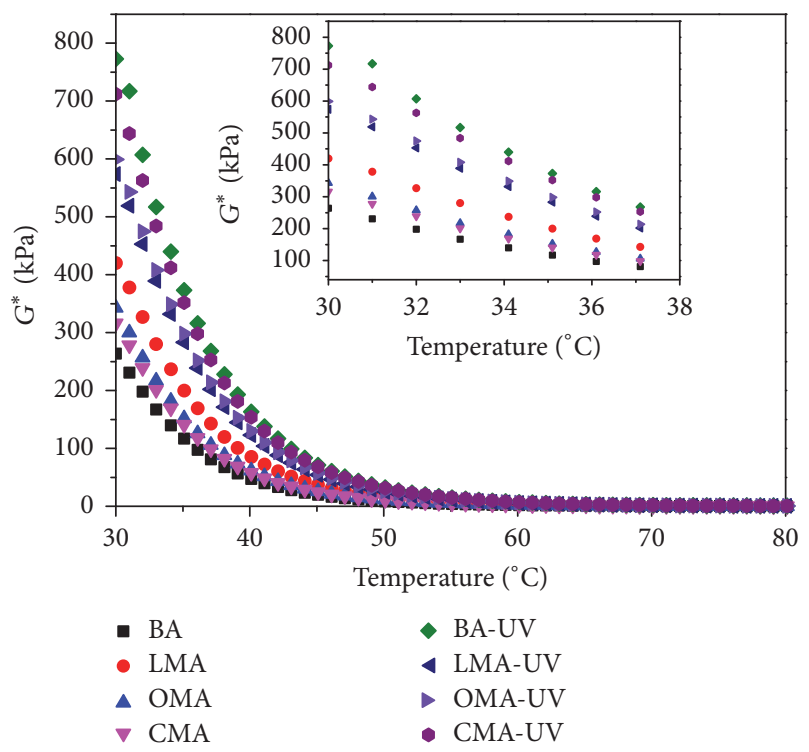

FIgUre 10: $\mathrm{G}^{*}$ of UV aged and unaged asphalt from $30^{\circ} \mathrm{C}$ to $80^{\circ} \mathrm{C}$.

after ageing from $30^{\circ} \mathrm{C}$ to $80^{\circ} \mathrm{C}$ is shown in Figure 11. It can be seen that $\delta$ of modified asphalt is higher than $\delta$ of base asphalt before UV ageing, which indicates that the time lag is shortened by modifiers. $\delta$ of asphalt after UV ageing is BA$\mathrm{UV}>\mathrm{CA}-\mathrm{UV}>\mathrm{OMA}-\mathrm{UV}>\mathrm{LMA}-\mathrm{UV}$. The results indicate that the anti-UV ageing effect of asphalt is improving with the additives and the anti-UV ageing effects of LDHs and OMMT are better than $\mathrm{CB}$, which is in concordance with results of complex modulus.

4.4.3. Low Temperature Sweep. $G^{*}$ of both base and modified asphalt before and after ageing from $-10^{\circ} \mathrm{C}$ to $30^{\circ} \mathrm{C}$ is

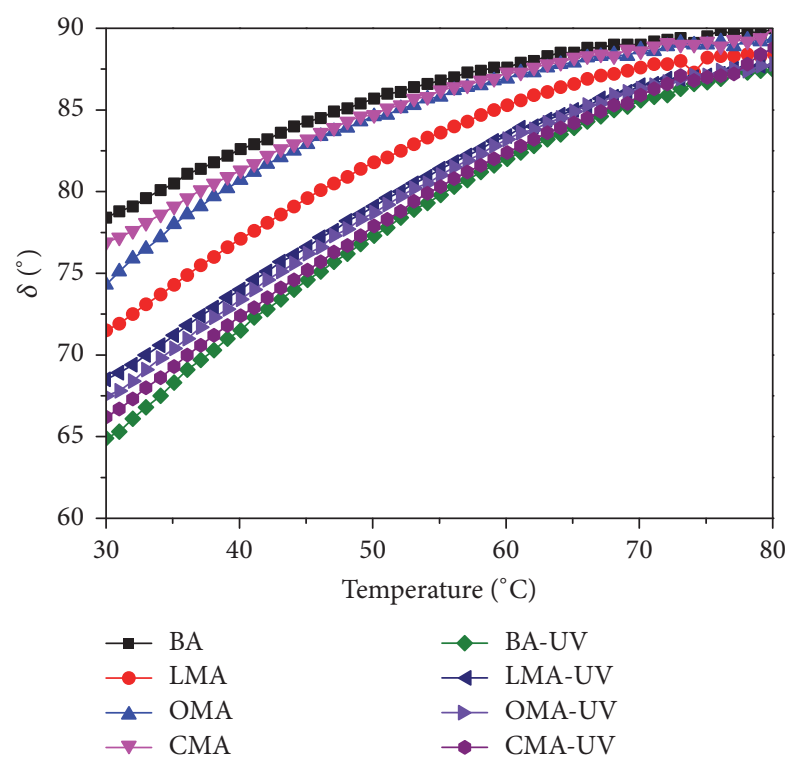

FIGURE 11: $\delta$ of UV aged and unaged asphalt from $30^{\circ} \mathrm{C}$ to $80^{\circ} \mathrm{C}$.

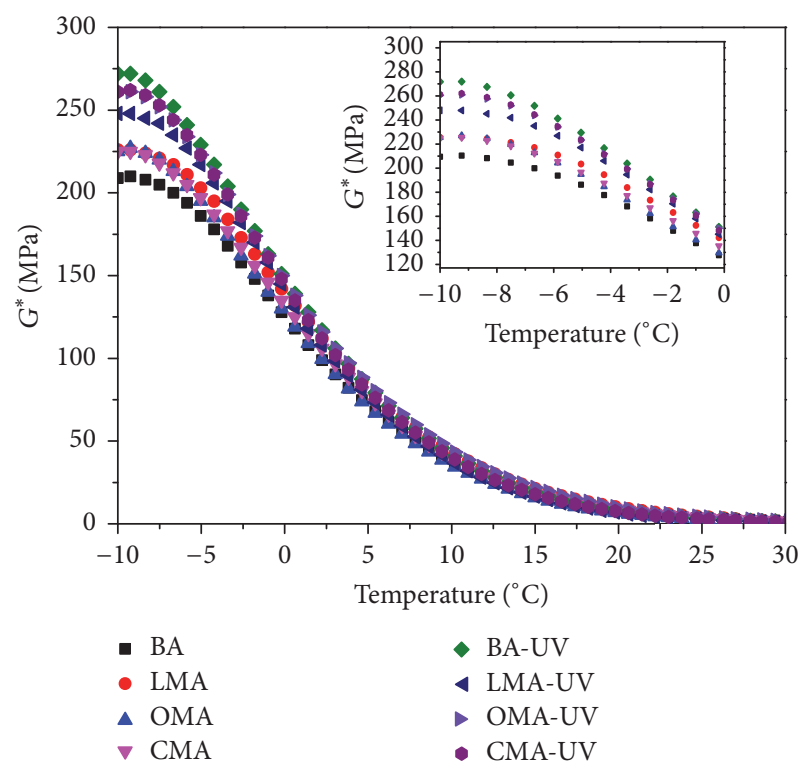

FIGURE 12: $\mathrm{G}^{*}$ of UV aged and unaged asphalt from $-10^{\circ} \mathrm{C}$ to $30^{\circ} \mathrm{C}$.

illustrated in Figure 12. It can be seen that modifiers used in this research increase $G^{*}$ of bitumen at low temperature. The phenomenon could be explained as asphalt ability of deformation resistance is increased with modifiers. $G^{*}$ of unaged modified bitumen is slightly higher than unaged base bitumen. The results show that UV ageing resistance of asphalt is increased with additives modifiers and $G^{*}$ of CMA-UV is higher than LMA, which means that the anti-UV ageing effects of LDHs are better than CB.

$\delta$ of base and modified asphalt before and after ageing from $-10^{\circ} \mathrm{C}$ to $30^{\circ} \mathrm{C}$ is shown in Figure $13 . \delta$ of base and modified asphalt before ageing is similar, which means that the ratio between viscous component and elastic component of asphalt is not changed by modifiers. $\delta$ of modified asphalt 
TABLE 3: $I_{\mathrm{C}=\mathrm{O}}$ and $I_{\mathrm{S}=\mathrm{O}}$ of UV aged and unaged asphalt.

\begin{tabular}{lcc}
\hline Asphalt & $I_{\mathrm{C}=\mathrm{O}}$ & $I_{\mathrm{S}=\mathrm{O}}$ \\
\hline BA & 0 & 0.00127 \\
BA-UV & 0.0482 & 0.0954 \\
LMA-UV & 0.0257 & 0.0623 \\
OMA-UV & 0.0318 & 0.0817 \\
CMA-UV & 0.0367 & 0.0785 \\
\hline
\end{tabular}

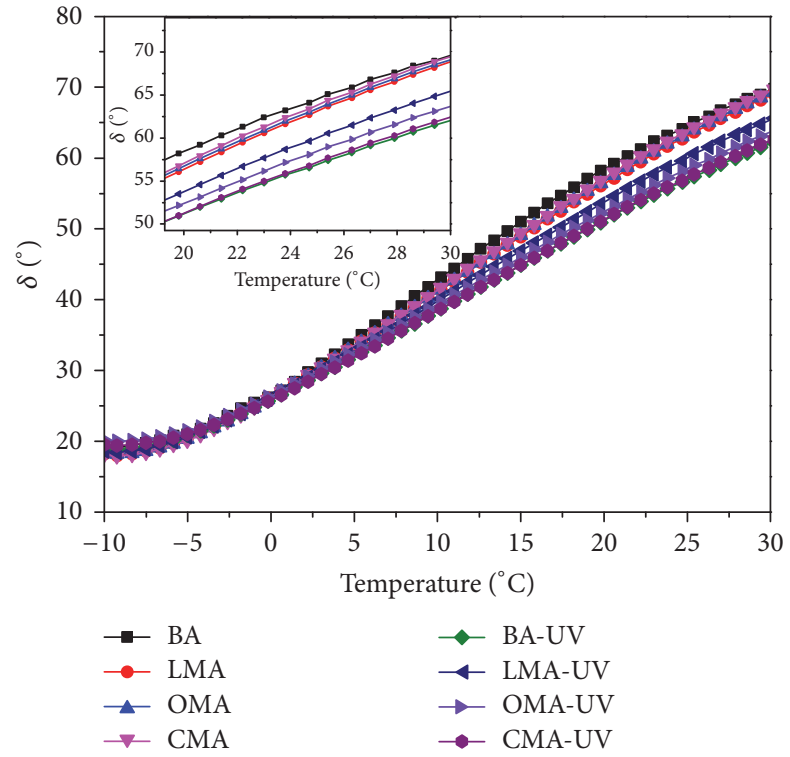

FIGURE 13: $\delta$ of UV aged and unaged asphalt from $-10^{\circ} \mathrm{C}$ to $30^{\circ} \mathrm{C}$.

after ageing is slightly higher than base bitumen. It indicated that UV resistance of modified bitumen is increased. Variation of $\delta$ of $\mathrm{CB}$ before and after UV ageing is slightly bigger than LMA, which means that the anti-UV ageing effects are better than $\mathrm{CB}$.

4.5. FTIR. With the increase of ageing degree, the content of carbonyl groups and sulfoxide groups is promoted [46]. From Table 3, it can be seen that the peak areas of carbonyl and butadiene double bonds of the BA are increased after $\mathrm{UV}$ ageing. Increasing $I_{\mathrm{C}=\mathrm{O}}$ and $I_{\mathrm{S}=\mathrm{O}}$ indicate absorbing more oxygen and more serious ageing index of asphalt after UV ageing. $I_{\mathrm{C}=\mathrm{O}}$ and $I_{\mathrm{S}=\mathrm{O}}$ of LMA, OMA, and CA are decreased compared to BA after UV ageing process. $I_{\mathrm{C}=\mathrm{O}}$ and $I_{\mathrm{S}=\mathrm{O}}$ of LDHs are minimums and $I_{\mathrm{C}=\mathrm{O}}$ and $I_{\mathrm{S}=\mathrm{O}}$ of carbon black are maximums. The effect of improving the UV ageing resistance of asphalt is highest with LDHs, medium with OMMT, and lowest with CB under the specific mixing amount. FTIR results show that the ageing extent of LMA is the lowest.

\section{Conclusions}

In this research, LDHs, OMMT, and CB were used as modifiers to prepare anti-UV ageing asphalt. Softening point, penetration, ductility, DSR test, and Fourier Transform Infrared
Spectroscopy (FTIR) test were conducted to evaluate anti-UV ageing effects of the three UV blocking materials. According to the discussion above, conclusions can be drawn as follows:

(1) The modifications of the asphalt with LDHs, OMMT, and $\mathrm{CB}$ could all improve the anti-UV ageing ability of asphalt. The physical properties of base asphalt were more influenced by UV ageing than those of modified asphalt. The increment of carbonyl groups and sulfoxide groups of modified asphalt is less than that of base asphalt.

(2) The complex modulus of asphalt before UV ageing is increased by adding the UV blocking additives, while the complex modulus of base asphalt after UV ageing is higher than modified asphalt. The phase angle of base asphalt after UV ageing is lower than that of modified asphalt. These results showed that the ageing extents of the three anti-UV ageing asphalt samples were much lower than that of base asphalt.

(3) LDHs could decrease the ageing rate of asphalt most effectively, followed by OMMT. CB showed the worst anti-UV ageing effect.

\section{Conflicts of Interest}

The authors declare that they have no conflicts of interest.

\section{Acknowledgments}

This work was financially supported by the National Basic Research Program of China (973 Program no. 2014CB932104), the Natural Science Foundation of China (no. 51508433), and the National Key Scientific Apparatus Development Program from the Ministry of Science and Technology of China (no. 2013YQ160501).

\section{References}

[1] Z. Chen, S. Wu, Y. Xiao, W. Zeng, M. Yi, and J. Wan, "Effect of hydration and silicone resin on Basic Oxygen Furnace slag and its asphalt mixture," Journal of Cleaner Production, vol. 112, pp. 392-400, 2016.

[2] P. Cui, S. Wu, Y. Xiao, M. Wan, and P. Cui, "Inhibiting effect of Layered Double Hydroxides on the emissions of volatile organic compounds from bituminous materials," Journal of Cleaner Production, vol. 108, pp. 987-991, 2015.

[3] P. Pan, S. Wu, Y. Xiao, and etal., "A review on hydronic asphalt pavement for energy harvesting and snow melting," Renewable \& Sustainable Energy Reviews, vol. 48, pp. 624-634, 2015. 
[4] X. Lu and U. Isacsson, "Effect of ageing on bitumen chemistry and rheology," Construction and Building Materials, vol. 16, no. 1, pp. 15-22, 2002.

[5] Y. Ruan, R. Davison, C. J. Glover, and etal., "Oxidation and viscosity hardening of polymer-modified asphalts," Energy \& Fuels, vol. 17, pp. 991-998, 2003.

[6] L. Xiaohu and U. Isacsson, "Chemical and rheological evaluation of ageing properties of SBS polymer modified bitumens," Fuel, vol. 77, no. 9-10, pp. 961-972, 1998.

[7] M. Poirier and H. Sawatzky, "Changes ih chemical component type composition and effect on rheoloqical properties of asphalts," Petroleum Science and Technology, vol. 10, no. 4-6, pp. 681-696, 2007.

[8] M. N. Siddiqui and M. F. Ali, "Studies on the aging behavior of the Arabian asphalts," Fuel, vol. 78, no. 9, pp. 1005-1015, 1999.

[9] Y. Ruan, R. R. Davison, and C. J. Glover, “The effect of long-term oxidation on the rheological properties of polymer modified asphalts," Fuel, vol. 82, no. 14, pp. 1763-1773, 2003.

[10] P. Cong, X. Wang, P. Xu, J. Liu, R. He, and S. Chen, "Investigation on properties of polymer modified asphalt containing various antiaging agents," Polymer Degradation and Stability, vol. 98, no. 12, pp. 2627-2634, 2013.

[11] E. Kalkornsurapranee, N. Vennemann, C. Kummerlöwe, and C. Nakason, "Novel thermoplastic natural rubber based on thermoplastic polyurethane blends: Influence of modified natural rubbers on properties of the blends," Iranian Polymer Journal, vol. 21, no. 10, pp. 689-700, 2012.

[12] M. N. Siddiqui and M. F. Ali, "Investigation of chemical transformations by NMR and GPC during the laboratory aging of Arabian asphalt," Fuel, vol. 78, no. 12, pp. 1407-1416, 1999.

[13] F. Durrieu, F. Farcas, and V. Mouillet, "The influence of UV aging of a styrene/butadiene/styrene modified bitumen: comparison between laboratory and on site aging," Fuel, vol. 86, no. 10-11, pp. 1446-1451, 2007.

[14] K. Yamaguchi, I. Sasaki, I. Nishizaki, S. Meiarashi, and A. Moriyoshi, "Effects of film thickness, wavelength, and carbon black on photodegradation of asphalt," Journal of the Japan Petroleum Institute, vol. 48, no. 3, pp. 150-155, 2005.

[15] Z. Feng, J. Yu, H. Zhang, D. Kuang, and L. Xue, "Effect of ultraviolet aging on rheology, chemistry and morphology of ultraviolet absorber modified bitumen," Materials and Structures, vol. 46, no. 7, pp. 1123-1132, 2012.

[16] S. Xu, J. Yu, C. Zhang, and Y. Sun, "Effect of ultraviolet aging on rheological properties of organic intercalated layered double hydroxides modified asphalt," Construction and Building Materials, vol. 75, pp. 421-428, 2015.

[17] H. Wu, L. Li, J. Yu, S. Xu, and D. Xie, "Effect of layered double hydroxides on ultraviolet aging properties of different bitumens," Construction and Building Materials, vol. 111, pp. 565-570, 2016.

[18] S. Xu, J. Yu, W. Wu, L. Xue, and Y. Sun, "Synthesis and characterization of layered double hydroxides intercalated by UV absorbents and their application in improving UV aging resistance of bitumen," Applied Clay Science, vol. 114, pp. 112119, 2015.

[19] H. L. Zhang, C. Z. Zhu, J. Y. Yu, C. Shi, and D. Zhang, "Influence of surface modification on physical and ultraviolet aging resistance of bitumen containing inorganic nanoparticles," Construction and Building Materials, vol. 98, pp. 735-740, 2015.
[20] V. B. Bojinov, I. P. Panova, and D. B. Simeonov, "Design and synthesis of polymerizable, yellow-green emitting 1,8naphthalimides containing built-in s-triazine UV absorber and hindered amine light stabilizer fragments," Dyes and Pigments, vol. 78, no. 2, pp. 101-110, 2008.

[21] A. Rehab and N. Salahuddin, "Nanocomposite materials based on polyurethane intercalated into montmorillonite clay," Materials Science and Engineering A, vol. 399, no. 1-2, pp. 368-376, 2005.

[22] A. Gultek, T. Seckin, Y. Onal, and M. Galip Icduygu, "Preparation and phenol captivating properties of polyvinyl pyrrolidone-montmorillonite hybrid materials," Journal of Applied Polymer Science, vol. 81, no. 2, pp. 512-519, 2001.

[23] Y. Qu, Y. Su, J. Sun, and etal., "Preparation of poly(styreneblock-acrylamide)/organic montmorillonite nanocomposites via reversible additionfragmentation chain transfer," Journal of Applied Polymer Science, vol. 110, pp. 387-391, 2008.

[24] C. Ouyang, S. Wang, Y. Zhang, and Y. Zhang, "Improving the aging resistance of styrene-butadiene-styrene tri-block copolymer modified asphalt by addition of antioxidants," Polymer Degradation and Stability, vol. 91, no. 4, pp. 795-804, 2006.

[25] J. Yu, L. Wang, X. Zeng, S. Wu, and B. Li, "Effect of montmorillonite on properties of styrene-butadiene-styrene copolymer modified bitumen," Polymer Engineering and Science, vol. 47, no. 9, pp. 1289-1295, 2007.

[26] J. Y. Yu, P. C. Feng, H. L. Zhang, and S. P. Wu, "Effect of organomontmorillonite on aging properties of asphalt," Construction and Building Materials, vol. 23, no. 7, pp. 2636-2640, 2009.

[27] H. Zhang, J. Yu, H. Wang, and L. Xue, "Investigation of microstructures and ultraviolet aging properties of organomontmorillonite/SBS modified bitumen," Materials Chemistry and Physics, vol. 129, no. 3, pp. 769-776, 2011.

[28] H. Zhang, J. Yu, and S. Wu, "Effect of montmorillonite organic modification on ultraviolet aging properties of SBS modified bitumen," Construction and Building Materials, vol. 27, no. 1, pp. 553-559, 2012.

[29] Q. Wang and D. O. Hare, "Recent advances in the synthesis and application of layered double hydroxide ( $\mathrm{LDH})$ nanosheets," Chemical Reviews, vol. 112, no. 7, pp. 4124-4155, 2012.

[30] Y. Huang, Z. Feng, H. Zhang, and J. Yu, "Effect of layered double hydroxides (LDHs) on aging properties of bitumen," Journal of Testing and Evaluation, vol. 40, no. 5, pp. 734-739, 2012.

[31] X. Liu, S. Wu, L. Pang, Y. Xiao, and P. Pan, "Fatigue properties of layered double hydroxides modified asphalt and its mixture," Advances in Materials Science and Engineering, vol. 2014, Article ID 868404, 6 pages, 2014.

[32] S. P. Wu, J. Han, L. Pang, M. Yu, and T. Wang, "Rheological properties for aged bitumen containing ultraviolate light resistant materials," Construction and Building Materials, vol. 33, pp. 133-138, 2012.

[33] A. Gomes, D. Cocke, D. Tran, and etal., "Layered double hydroxides in energy research: advantages and challenges," in Energy Technology 2015: Carbon Dioxide Management and Other Technologies, pp. 309-316, USA, 2015.

[34] E. P. Giannelis, "Polymer layered silicate nanocomposites," Advanced Materials, vol. 8, no. 1, pp. 29-35, 1996.

[35] G. Liu, Characterization and Identification of Bituminous Materials Modified with Montmorillonite Nanoclay, TU, Delft, Delft University of Technology, 2011.

[36] W. Zhu, D. E. Miser, W. G. Chan, and M. R. Hajaligol, "HRTEM investigation of some commercially available furnace carbon blacks," Carbon, vol. 42, no. 8-9, pp. 1841-1845, 2004. 
[37] F. Cataldo, "The impact of a fullerene-like concept in carbon black science," Carbon, vol. 40, no. 2, pp. 157-162, 2002.

[38] N. Pieri, "Étude du vieillissement simulé et in situ des bitumes routiers par IRTF et fluorescence UV en excitation-emission synchrones," d'Aix-Marseille 3, 1994.

[39] J. Lamontagne, P. Dumas, V. Mouillet, and J. Kister, "Comparison by Fourier transform infrared (FTIR) spectroscopy of different ageing techniques: application to road bitumens," Fuel, vol. 80, no. 4, pp. 483-488, 2001.

[40] F. Morea, J. O. Agnusdei, and R. Zerbino, "Comparison of methods for measuring zero shear viscosity in asphalts," Materials and Structures/Materiaux et Constructions, vol. 43, no. 4, pp. 499-507, 2010.

[41] O. V. Laukkanen, T. Pellinen, and M. Makowska, "Exploring the observed rheological behaviour of in-situ aged and fresh bitumen employing the colloidal model proposed for bitumen," Multi-Scale Modeling and Characterization of Infrastructure Materials, pp. 185-197, 2013.

[42] G. Airey, B. Rahimzadeh, and A. Collop, "Linear viscoelastic performance of asphaltic materials," Road Materials and Pavement Design, vol. 4, no. 3, pp. 269-292, 2003.

[43] X. Lu and U. Isacsson, "Rheological characterization of styrenebutadiene-styrene copolymer modified bitumens," Construction and Building Materials, vol. 11, no. 1, pp. 23-32, 1997.

[44] F. Xiao, S. N. Amirkhanian, M. Karakouzian, and M. Khalili, "Rheology evaluations of WMA binders using ultraviolet and PAV aging procedures," Construction and Building Materials, vol. 79, pp. 56-64, 2015.

[45] F. Xiao, S. Amirkhanian, H. Wang, and P. Hao, "Rheological property investigations for polymer and polyphosphoric acid modified asphalt binders at high temperatures," Construction and Building Materials, vol. 64, pp. 316-323, 2014.

[46] V. Mouillet, J. Lamontagne, F. Durrieu, J.-P. Planche, and L. Lapalu, "Infrared microscopy investigation of oxidation and phase evolution in bitumen modified with polymers," Fuel, vol. 87, no. 7, pp. 1270-1280, 2008. 

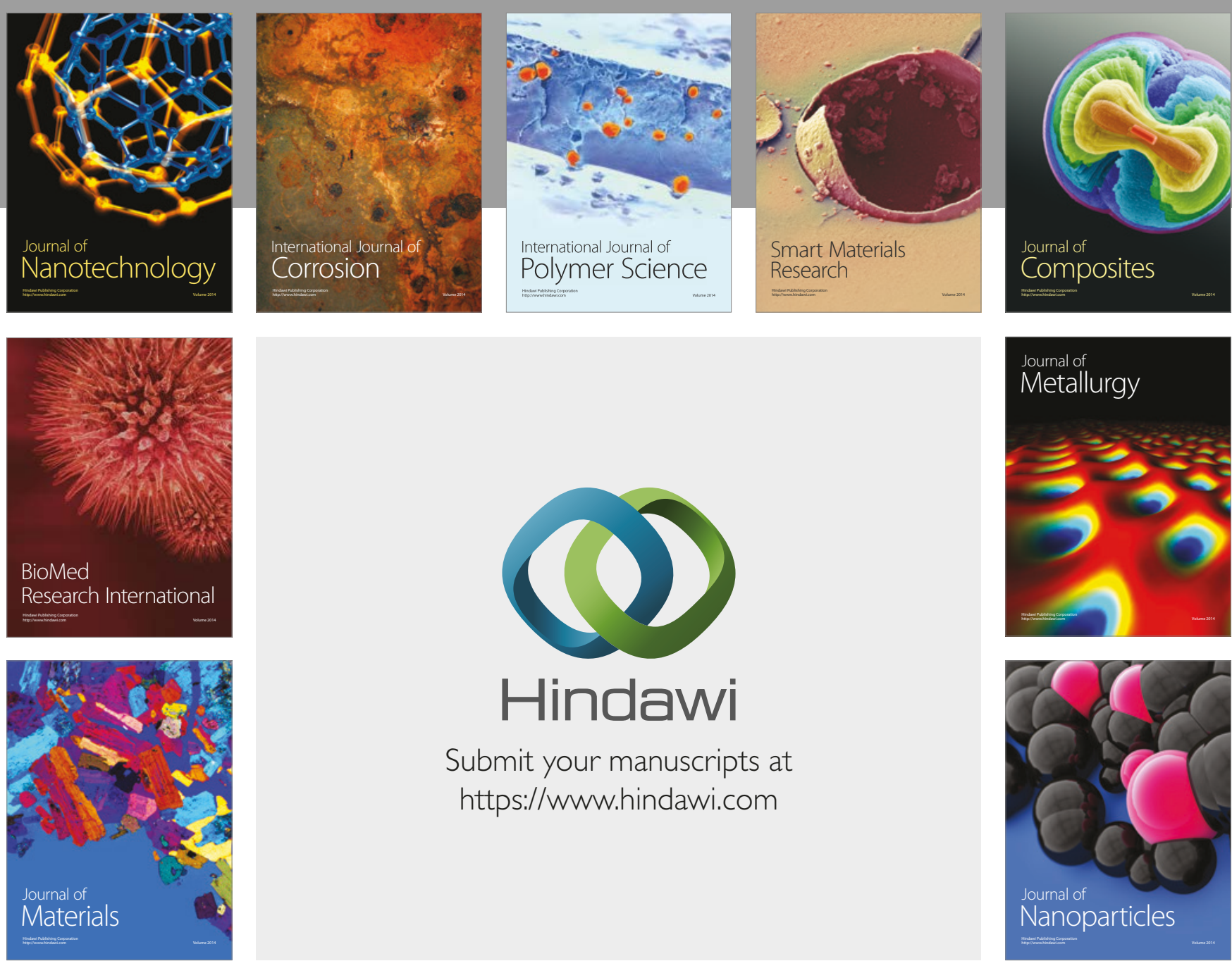

\section{Hindawi}

Submit your manuscripts at

https://www.hindawi.com
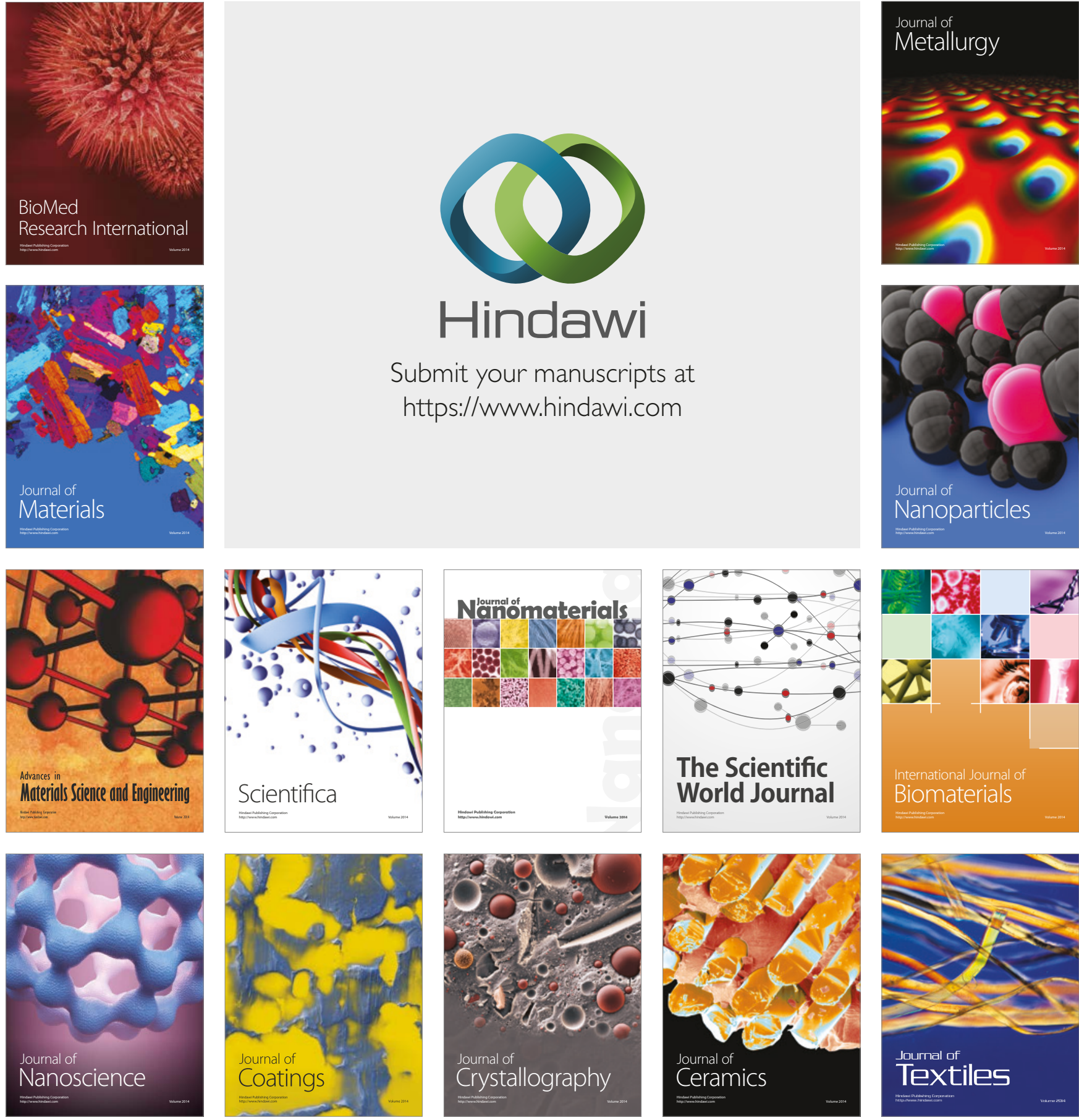

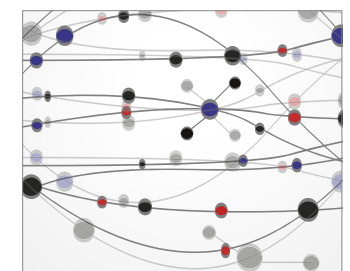

The Scientific World Journal
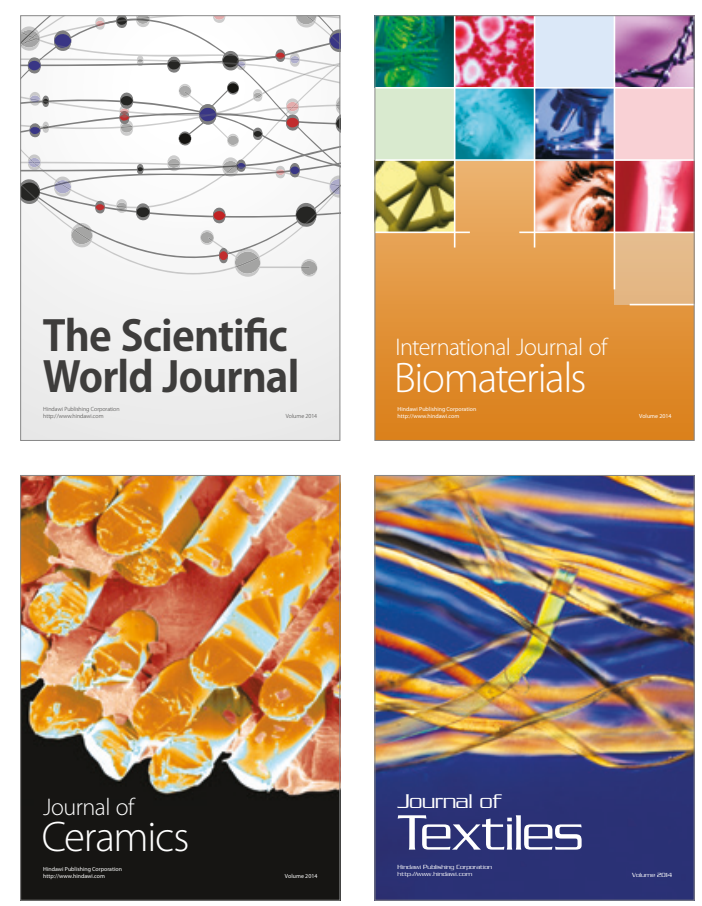